\title{
OPTIMIZATION OF FOUR-BUTTON BEAM POSITION MONITOR CONFIGURATION FOR SMALL-GAP VACUUM CHAMBERS
}

The submitted manuscript has been authored
by a contractor of the U.S. Government inder contract No. W-31-109ENG-38 Accordingly, the U.S. Government retains a nonexclusive, royalty-free license to publish or reproduce the published form of this contribution, or allow others to do so, for U. S. Government purposes.
S. H. Kim

March 27, 1998
RECEIVED

MAY 261998

Summary - Induced charges on a four-button beam position monitor (BPMB attached on a beam chamber of narrow rectangular cross sections are calculated . Q $_{2}-\mathrm{D}$ width/height $(2 \mathrm{w} / 2 \mathrm{~h})>>1$, over $90 \%$ of the induced charges are distributed within a distance of $2 \mathrm{~h}$ from the charged beam position in the direction of the chamber width. Therefore, a four-button system with a button diameter of $(2 \sim 2.5) \mathrm{h}$ and no button offset from the beam position is the most efficient configuration. The four-button BPMs used for 8-mm and $5-\mathrm{mm}$ chambers in the APS have relatively low sensitivities because the button locations are outside the range where the induced charge densities are low and the button diameters are less than $2 \mathrm{~h}$. Using derived formulae, button sensitivities and beam position coefficients are calculated for the buttons of the most efficient case and of the 8-mm and 5-mm chambers. The formulae may be used to validate the method of computer modeling for BPM buttons on a beam chamber of an arbitrary cross section.

\section{INTRODUCTION}

For a point charge $\lambda$ moving with a constant velocity $\mathrm{v}$ in the $\mathrm{z}$ direction, the electric field in the laboratory frame derived from the Lienard-Wiechert potential is given by [1]

$$
E=\frac{\lambda}{4 \pi \varepsilon_{0} r^{2}} \frac{1-\beta^{2}}{\left(1-\beta^{2} \sin ^{2} \theta\right)^{3 / 2}},
$$

where $\beta=v / c, c$ is the velocity of light, $r$ is the distance from the position of the charge to an observation point, and $\theta$ is the angle between the $\mathrm{z}$-direction and the observation point at the position of the charge. By integrating $E \cdot 2 \pi r^{2} \sin \theta d \theta$, the electric flux between two given angles can be calculated. For $\gamma=1 / \sqrt{1-\beta^{2}}>1$, a fraction $\mathrm{f}$ of the total electric flux is concentrated within an angle of $\pm 1 / \gamma\left(f / \sqrt{1-f^{2}}\right)$ of the transverse plane to the $\mathrm{z}$ direction. For example, for $\gamma=2 \times 10^{3}, 90 \%$ of the total electric flux is concentrated within an angle of $\pm 1.04 \mathrm{mrad}$. In this note, therefore, calculations of induced charges on button-type pickups for a BPM system are considered as a 2-D electrostatic problem.

\section{IMAGE CHARGES}

Assuming that the width of the beam chamber in Fig. 1 is much larger than the height $(w>h)$, the induced charges are calculated by the methods of image charge. The beam chamber is also assumed to have a high electric conductivity and is grounded. Then the vertical positions of the positive and negative image charges of a charge $\lambda$ at $\left(\mathrm{x}_{0}, \mathrm{y}_{0}\right)$ are given by

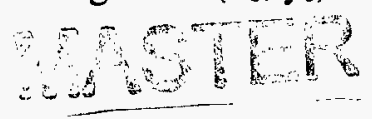




\section{DISCLAIMER}

This report was prepared as an account of work sponsored by an agency of the United States Government. Neither the United States Government nor any agency thereof, nor any of their employees, makes any warranty, express or implied, or assumes any legal liability or responsibility for the accuracy, completeness, or usefulness of any information, apparatus, product, or process disclosed, or represents that its use would not infringe privately owned rights. Reference herein to any specific commercial product, process, or service by trade name, trademark, manufacturer, or otherwise does not necessarily constitute or imply its endorsement, recommendation, or favoring by the United States Government or any agency thereof. The views and opinions of authors expressed herein do not necessarily state or reflect those of the United States Government or any agency thereof. 


$$
\begin{array}{ll}
\quad+\lambda \text { at } y=2 m(a+b)+y_{0}=4 m h+y_{0}, & (m=-\infty, 0, \infty) \\
\text { and }-\lambda \text { at } y=2 a+2 m(a+b)+y_{0}=2 a+4 m h+y_{0} & (m=-\infty, 0, \infty) \\
\text { with } a=h-y_{0} \text { and } b=h+y_{0} . &
\end{array}
$$

For ease of calculation the vertical position for $(-\lambda)$ is shifted by $2 h$ so that $y^{\prime}=y-2 h$ $=4 \mathrm{mh}-\mathrm{y}_{0}$. (In the 3-D geometry the charge $\lambda$ is a line-charge density along the $\mathrm{z}$ direction.)

Then the electrostatic potential distribution $\Phi(\mathrm{x}, \mathrm{y})$ within the chamber may be calculated from [2]

$$
\Phi(x, y)=\frac{-\lambda}{2 \pi \varepsilon_{0}} \ln \frac{\prod_{m=-\infty}^{\infty}\left|z-z_{m}\right|}{\prod_{m=-\infty}^{\infty}\left|z^{\prime}-z_{m}^{\prime}\right|}=\frac{-\lambda}{2 \pi \varepsilon_{0}} \ln \frac{\left|z-z_{0}\right| \prod_{m=1}^{\infty}\left|\left(z-z_{m}\right)\left(z-z_{-m}\right)\right|}{\left|z^{\prime}-z_{0}^{\prime}\right| \prod_{m=1}^{\infty}\left|\left(z^{\prime}-z_{m}^{\prime}\right)\left(z^{\prime}-z_{-m}^{\prime}\right)\right|}
$$

where $\varepsilon_{0}$ is the permittivity constant, $\mathrm{z}=\mathrm{x}+\mathrm{i} y, \mathrm{z}^{\prime}=\mathrm{x}+\mathrm{i} \mathrm{y}^{\prime}, \mathrm{z}_{ \pm \mathrm{m}}=\mathrm{x}_{0}+\mathrm{i}\left( \pm 4 \mathrm{mh}+\mathrm{y}_{0}\right)$, and $\mathrm{z}^{\prime} \pm \mathrm{m}=\mathrm{x}_{\mathrm{o}}+\mathrm{i} \mathrm{y}^{\prime}=\mathrm{x}_{\mathrm{o}}+\mathrm{i}\left( \pm 4 \mathrm{mh}-\mathrm{y}_{\mathrm{o}}\right)$. Using the relation

$$
\sin z=z \prod_{n=1}^{\infty}\left[1-\left(\frac{z}{n \pi}\right)^{2}\right]
$$

Eq. (3) may be simplified to a closed form

$$
\begin{aligned}
\Phi(x, y) & =\frac{-\lambda}{2 \pi \varepsilon_{0}} \operatorname{Re}\left\{\ln \frac{\sin \pi\left(\frac{z-x_{o}-i y_{o}}{4 h i}\right)}{\sin \pi\left(\frac{z^{\prime}-x_{o}+i y_{o}}{4 h i}\right)}\right\} \\
& =\frac{-\lambda}{4 \pi \varepsilon_{0}} \ln \frac{\cosh \pi \frac{x-x_{o}}{2 h}-\cos \pi \frac{y-y_{o}}{2 h}}{\cosh \pi \frac{x-x_{o}}{2 h}-\cos \pi \frac{y^{\prime}+y_{o}}{2 h}}=\frac{-\lambda}{4 \pi \varepsilon_{0}} \ln \frac{\cosh \pi \frac{x-x_{o}}{2 h}-\cos \pi \frac{y-y_{o}}{2 h}}{\cosh \pi \frac{x-x_{o}}{2 h}+\cos \pi \frac{y+y_{o}}{2 h}},
\end{aligned}
$$

where $y^{\prime}$ is shifted back to $y+2 h$ in the final expression.

The induced charge densities per $\mathrm{x} / \mathrm{h}$ in the top and bottom surfaces of the chamber, $\sigma_{\mathrm{t}}$ and $\sigma_{b}$, are calculated from $\left[-\varepsilon_{\mathrm{o}} \mathrm{d} \Phi / \mathrm{dy}\right]_{\mathrm{y}= \pm \mathrm{h}}$ :

$$
\begin{aligned}
\sigma_{t} & =-\frac{\lambda}{4} \frac{\cos p y_{o}}{\cosh p\left(x-x_{o}\right)-\sin p y_{o}}, \\
\sigma_{b} & =-\frac{\lambda}{4} \frac{\cos p y_{o}}{\cosh p\left(x-x_{o}\right)+\sin p y_{o}}
\end{aligned}
$$


Here $\mathrm{p}=\pi / 2$ and by setting $\mathrm{h}=1$ the coordinate system is normalized to the half height of the chamber. (The normalization is used for Eqs. (5) - (10).) By adding up the induced charges in the top and bottom surfaces in Eq. (5), the total induced charge, which should be proportional to the sum signal for a typical four-button BPM system of Fig. 1, is given by

$$
\begin{aligned}
Q_{s} & =Q_{s}\left(x_{2}\right)-Q_{s}\left(x_{1}\right)=\int_{x 1}^{x 2}\left(\sigma_{t}+\sigma_{b}\right) d x+\int_{-x 2}^{-x 1}\left(\sigma_{t}+\sigma_{b}\right) d x \\
& =-\lambda \frac{1}{2} \int_{x 1}^{x 2}\left\{\frac{\cos p y_{o} \cosh p\left(x-x_{o}\right)}{\cosh ^{2} p\left(x-x_{o}\right)-\sin ^{2} p y_{o}}+\frac{\cos p y_{o} \cosh p\left(x+x_{o}\right)}{\cosh ^{2} p\left(x+x_{o}\right)-\sin ^{2} p y_{o}}\right\} d x .
\end{aligned}
$$

The induced charges proportional to the signals for the vertical and horizontal positions of the charged beam, $Q_{y}$ and $Q_{x}$, may be calculated from Eq. (5):

$$
\begin{aligned}
Q_{y} & =Q_{y}\left(x_{2}\right)-Q_{y}\left(x_{1}\right)=\int_{x 1}^{x 2}\left(\sigma_{t}-\sigma_{b}\right) d x+\int_{-x 2}^{-x 1}\left(\sigma_{t}-\sigma_{b}\right) d x \\
& =-\lambda \frac{1}{2} \int_{x 1}^{x 2}\left\{\frac{\sin p y_{o} \cos p y_{o}}{\cosh ^{2} p\left(x-x_{o}\right)-\sin ^{2} p y_{o}}+\frac{\sin p y_{o} \cos p y_{o}}{\cosh ^{2} p\left(x+x_{o}\right)-\sin ^{2} p y_{o}}\right\} d x, \\
Q_{x} & =Q_{x}\left(x_{2}\right)-Q_{x}\left(x_{1}\right)=\int_{x 1}^{x 2}\left(\sigma_{t}+\sigma_{b}\right) d x-\int_{-x 2}^{-x 1}\left(\sigma_{t}+\sigma_{b}\right) d x \\
& =-\lambda \frac{1}{2} \int_{x 1}^{x 2}\left\{\frac{\cos p y_{o} \cosh p\left(x-x_{o}\right)}{\cosh ^{2} p\left(x-x_{o}\right)-\sin ^{2} p y_{o}}-\frac{\cos p y_{o} \cosh p\left(x+x_{o}\right)}{\cosh ^{2} p\left(x+x_{o}\right)-\sin ^{2} p y_{o}}\right\} d x .
\end{aligned}
$$

Here $Q_{y}$ and $Q_{x}$ are the differences in the induced charges between the top and bottom, and right and left buttons, respectively. As one expects from beam position measurements, $\mathrm{Q}_{\mathrm{y}}$ is an odd function in $\mathrm{y}_{0}$ and even in $\mathrm{x}_{0}$, and $\mathrm{Q}_{\mathrm{x}}$ is the opposite. After Taylor expansions up to the third order in the charged beam position $\left(\mathrm{x}_{0}, \mathrm{y}_{\mathrm{o}}\right)$, indefinite integrals of Eqs. (6) - (8) are given by

$$
\begin{gathered}
\frac{Q_{s}(x)}{-\lambda}=\frac{1}{p} \tan ^{-1}[\sinh p x]+\left(y_{o}{ }^{2}-x_{o}{ }^{2}\right) \frac{p \sinh p x}{2 \cosh ^{2} p x}+y_{o}{ }^{2} x_{o}{ }^{2} \frac{p^{3}}{4}\left(\frac{\sinh p x}{\cosh ^{2} p x}-\frac{6 \sinh p x}{\cosh ^{4} p x}\right), \\
\frac{Q_{y}(x)}{-\lambda}=y_{o}\left[\tanh p x+x_{o}{ }^{2} p^{2} \frac{-\sinh p x}{\cosh ^{3} p x}\right]+y_{o}{ }^{3}\left[p^{2} \frac{\sinh p x}{3 \cosh ^{3} p x}+x_{o}{ }^{2} p^{4}\left(\frac{2 \sinh p x}{3 \cosh ^{3} p x}-\frac{2 \sinh p x}{\cosh ^{5} p x}\right)\right], \\
\frac{Q_{x}(x)}{-\lambda}=x_{o}\left[-\operatorname{sech}(p x)+y_{o}{ }^{2} p^{2}\left\{\frac{1}{2} \operatorname{sech}(p x)-\operatorname{sech}(p x)\right\}\right]+x_{o}^{3}\left[\frac { p ^ { 2 } } { 6 } \left\{2 \operatorname{sech} h^{3}(p x)\right.\right. \\
\left.-\operatorname{sech}(p x)\}+y_{o}{ }^{2} p^{4}\left\{2 \operatorname{sech} h^{5}(p x)-\frac{5}{3} \operatorname{sech}^{3}(p x)+\frac{1}{12} \operatorname{sech}(p x)\right\}\right] .
\end{gathered}
$$


To the first order in $y_{0} / h$ and $x_{0} / h$, calculations of the induced charges from $x_{1}=0$ to $x_{2}=\infty$ in Eq. (9) give $Q_{y}=-\lambda y_{0} / h, Q_{x}=-\lambda x_{0} / h$, and the total induced charge $Q_{s}=-\lambda$ as expected. The above three equations will be used to calculate the button sensitivity and coefficients for $y_{0} / h$ and $x_{0} / h$. The derivatives of $Q_{s}(x), Q_{y}(x)$, and $Q_{x}(x)$ with respect to $x / h$ may be called "the effective induced charge densities for the sum, vertical, and horizontal signals." Their first terms are

$$
\begin{aligned}
& d Q_{s}(x) / d x=-\lambda \operatorname{sech}(p x), \\
& d Q_{y}(x) / d x=-y_{0} p \lambda \operatorname{sech} h^{2}(p x), \\
& d Q_{x}(x) / d x=-x_{0} p \lambda \sinh (p x) \sec h^{2}(p x) .
\end{aligned}
$$

Equation (10) and the first terms of Eq. (9) are plotted in Fig. 2. Here the induced charges and the respective densities for $\mathrm{Q}_{s}, \mathrm{Q}_{\mathrm{y}}$, and $\mathrm{Q}_{\mathrm{x}}$ are denoted as sum, vert, and horz in the figure legend, respectively, with units of $-\lambda,-\lambda y_{0} / h$, and $-\lambda x_{0} / h$. (The units of the charge densities for $Q_{s}, Q_{y}$, and $Q_{x}$ should be $-\lambda / h,-\lambda y_{0} / h^{2}$, and $-\lambda x_{0} / h^{2}$ if plotted in $x$ instead of $x / h$.) For small buttons (e.g. $x / h<0.5$ ), when the beam is located near the origin, the horizontal beam displacement is not as sensitive to changes in the distances between the beam and the buttons as the vertical beam displacement. This makes the density distribution for $\mathrm{Q}_{\mathrm{x}}$ broad with the peak near $x / h=0.6$. The density for $Q_{y}$, on the other hand, has its peak at $x / h=0$. This implies that, when the measurements of vertical displacements are critical for a beam chamber of small height, the location of the buttons should include the range of small $\mathrm{x} / \mathrm{h}$. For buttons located in the range of $\mathrm{x}=0-2 \mathrm{~h}$ with button diameter of $2 \mathrm{~h}$, for example, over $94 \%, 99 \%$, and $91 \%$ of the available sensitivities for sum, vert, and horz can be registered on the buttons. Therefore, any buttons located more than $2 \mathrm{~h}$ (one chamber height) from the beam position in the horizontal direction would be very inefficient.

Shown in Fig. 3 are 3-D plots and their contours for $Q_{s}$, $Q_{y}$, and $Q_{x}$. The negative position of $x_{1}$ is possible by rotating the four-button system with respect to the vertically symmetrical axis. For $\mathrm{x}_{1}=0$ and a button diameter $\mathrm{d}$ larger than $2 \mathrm{~h}$, it is seen that $\mathrm{Q}_{\mathrm{s}}, \mathrm{Q}_{\mathrm{y}}$, and $\mathrm{Q}_{\mathrm{x}}$ do saturate as already expected from Fig. 2 . When the buttons are extended to both sides of the $\mathrm{x}$-axis by rotating the four-button system and the diameter is larger than $4 \mathrm{~h}$, the values of $\mathrm{Q}_{\mathrm{s}}$ and $Q_{y}$ increase by a factor of 2 because most parts of the buttons are still located within $x / h$ $<2$ where the charge densities are high. On the other hand, $Q_{x}$ decreases because the charge density for $Q_{x}$ in Eq. (10) is asymmetric with respect to $x$. Therefore, a four-button system with a button diameter of approximately $(2 \sim 2.5) \mathrm{h}$ and a button offset of $\mathrm{x}_{1}=0$ would collect nearly all the induced charges and be the most efficient.

\section{BUTTON SENSITIVITIES}

It is seen from Figs. 2 and 3 that button sensitivities of over $90 \%$ of the induced charges can be obtained for a button diameter of $(2 \sim 2.5) \mathrm{h}$ and a button offset of $\mathrm{x}_{1}=0$. With $\mathrm{x}_{1}=0$ and $d=2 h$, where the button diameter $d$ is $\left(x_{2}-x_{1}\right) h, Q_{s}, Q_{y}, Q_{x}$, and their normalized values to $Q_{s}$ are calculated from Eqs. (6) - (8). The results give an optimized BPM configuration and are plotted in Fig. 4 as functions of the normalized beam position $\left(\mathrm{y}_{0} / \mathrm{h}, \mathrm{x}_{0} / \mathrm{h}\right)$. The button 
sensitivities and coefficients for $\mathrm{y}_{0} / \mathrm{h}$ and $\mathrm{x}_{0} / \mathrm{h}$ for the optimized configuration are calculated from Eq. (9).

Optimized configuration:

$$
\begin{aligned}
& \mathrm{Q}_{s}=0.945\left[1.0+0.07143\left\{\left(\mathrm{y}_{0} / \mathrm{h}\right)^{2}-\left(\mathrm{x}_{0} / \mathrm{h}\right)^{2}\right\}+0.0842\left(\mathrm{x}_{0} / \mathrm{h}\right)^{2}\left(\mathrm{y}_{0} / \mathrm{h}\right)^{2}\right], \\
& \mathrm{Q}_{\mathrm{y}}=0.9963\left[\left\{1.0-0.01836\left(\mathrm{x}_{0} / \mathrm{h}\right)^{2}\right\}\left(\mathrm{y}_{\mathrm{o}} / \mathrm{h}\right)+\left\{0.00612+0.0295\left(\mathrm{x}_{0} / \mathrm{h}\right)^{2}\right\}\left(\mathrm{y}_{0} / \mathrm{h}\right)^{3},\right. \\
& \mathrm{Q}_{\mathrm{x}}=0.9137\left[\left\{1.0+1.4649\left(\mathrm{y}_{0} / \mathrm{h}\right)^{2}\right\}\left(\mathrm{x}_{0} / \mathrm{h}\right)-\left\{0.4883+2.7354\left(\mathrm{y}_{\mathrm{o}} / \mathrm{h}\right)^{2}\right\}\left(\mathrm{x}_{0} / \mathrm{h}\right)^{3}\right], \\
& \mathrm{Q}_{\mathrm{y}} / \mathrm{Q}_{\mathrm{s}}=1.0542\left[\left\{1+0.0531\left(\mathrm{x}_{0} / \mathrm{h}\right)^{2}\right\}\left(\mathrm{y}_{0} / \mathrm{h}\right)-\left\{0.0653+0.0631\left(\mathrm{x}_{0} / \mathrm{h}\right)^{2}\right\}\left(\mathrm{y}_{0} / \mathrm{h}\right)^{3}\right], \\
& \mathrm{Q}_{\mathrm{x}} / \mathrm{Q}_{s}=0.9669\left[\left\{1+1.3935\left(\mathrm{y}_{0} / \mathrm{h}\right)^{2}\right\}\left(\mathrm{x}_{0} / \mathrm{h}\right)-\left\{0.4169+2.6159\left(\mathrm{y}_{\mathrm{o}} / \mathrm{h}\right)^{2}\right\}\left(\mathrm{x}_{0} / \mathrm{h}\right)^{3}\right] .
\end{aligned}
$$

It is seen from Fig. 4(a) and Eq. (11) that the vertical signal $\mathrm{Q}_{\mathrm{y}}$ and $\mathrm{Q}_{\mathrm{y}} / \mathrm{Q}_{\mathrm{s}}$ within $\pm 0.7 \mathrm{y}_{0} / \mathrm{h}$ have excellent linearity in $y_{0} / h$ and $x_{0} / h$. This is particularly important since vertical measurements are generally critical in a small chamber height. The horizontal signals $Q_{x}$ and $\mathrm{Q}_{\mathrm{x}} / \mathrm{Q}_{\mathrm{s}}$, on the other hand, are less linear compared to those for the vertical as seen from Fig. 4(b) and the coefficients of $y_{0} / h$ and $x_{0} / h$ in Eq. (11).

In the APS storage ring, beam chambers with relatively small chamber heights are used for the insertion devices (IDs) in the straight sections. Several four-button BPMs with button diameters of $4 \mathrm{~mm}$ and button-center separations of $9.65 \mathrm{~mm}$ have been installed for chamber heights of $8 \mathrm{~mm}\left(\mathrm{~h}=4 \mathrm{~mm}, \mathrm{x}_{1}=0.7075 \mathrm{~h}, \mathrm{x}_{2}=1.7075 \mathrm{~h}\right.$, diameter $\left.=1.0 \mathrm{~h}\right)$ and $5 \mathrm{~mm}(\mathrm{~h}=2.5$ $\mathrm{mm}, \mathrm{x}_{1}=1.132 \mathrm{~h}, \mathrm{x}_{2}=2.732 \mathrm{~h}$, diameter $=1.6 \mathrm{~h}$ ). One can see from Fig. 2 that these buttons are located at relatively inefficient positions compared to an ideal case of $x_{1}=0$ and $x_{2}=2 h$. The button sensitivities and $y_{0}$ and $x_{0}$ coefficients for the two chambers are calculated from Eq. (9).

$$
\begin{aligned}
& \text { APS ID chamber }(2 \mathrm{~h}=8 \mathrm{~mm}) \text { : } \\
& \mathrm{Q}_{s}=0.3178\left[1.0+0.0529\left\{\mathrm{x}_{\mathrm{o}}{ }^{2}-\mathrm{y}_{\mathrm{o}}{ }^{2}\right\}+0.00778 \mathrm{x}_{\mathrm{o}}{ }^{2} \mathrm{y}_{\mathrm{o}}{ }^{2}\right], \\
& \mathrm{Q}_{\mathrm{y}}=0.0465\left[\left\{1.0+0.2199 \mathrm{x}_{\mathrm{o}}{ }^{2}\right\} \mathrm{y}_{\mathrm{o}}+\left\{-0.0733+0.00228 \mathrm{x}_{\mathrm{o}}{ }^{2}\right\} \mathrm{y}_{\mathrm{o}}{ }^{3},\right. \\
& \mathrm{Q}_{\mathrm{x}}=0.1144\left[\left\{1.0-0.00738 \mathrm{y}_{\mathrm{o}}{ }^{2}\right\} \mathrm{x}_{\mathrm{o}}+\left\{0.00246+0.00827 \mathrm{y}_{\mathrm{o}}{ }^{2}\right\} \mathrm{x}_{\mathrm{o}}{ }^{3}\right], \\
& \mathrm{Q}_{\mathrm{y}} / \mathrm{Q}_{\mathrm{s}}=0.1464\left[\left\{1+0.1669 \mathrm{x}_{\mathrm{o}}{ }^{2}\right\} \mathrm{y}_{\mathrm{o}}+\left\{-0.2033+0.00502 \mathrm{x}_{\mathrm{o}}{ }^{2}\right\} \mathrm{y}_{\mathrm{o}}{ }^{3}\right], \\
& \mathrm{Q}_{\mathrm{x}} / \mathrm{Q}_{\mathrm{s}}=0.360\left[\left\{1+0.0456 \mathrm{y}_{\mathrm{o}}{ }^{2}\right\} \mathrm{x}_{\mathrm{o}}+\left\{-0.5049+0.00229 \mathrm{y}_{\mathrm{o}}{ }^{2}\right\} \mathrm{x}_{\mathrm{o}}{ }^{3}\right] .
\end{aligned}
$$

The smallest aperture APS chamber $(2 \mathrm{~h}=5 \mathrm{~mm})$ :

$$
\begin{aligned}
& \mathrm{Q}_{s}=0.1957\left[1.0+0.1817\left\{\mathrm{x}_{\mathrm{o}}{ }^{2}-\mathrm{y}_{\mathrm{o}}{ }^{2}\right\}-0.0104 \mathrm{x}_{0}{ }^{2} \mathrm{y}_{\mathrm{o}}{ }^{2}\right], \\
& \mathrm{Q}_{\mathrm{y}}=0.02205\left[\left\{1.0+0.7246 \mathrm{x}_{\mathrm{o}}{ }^{2}\right\} \mathrm{y}_{\mathrm{o}}-\left\{0.2415+0.1285 \mathrm{x}_{0}{ }^{2}\right\} \mathrm{y}_{\mathrm{o}}{ }^{3},\right.
\end{aligned}
$$




$$
\begin{aligned}
& \mathrm{Q}_{\mathrm{x}}=0.1205\left[\left\{1.0-0.1509 \mathrm{y}_{\mathrm{o}}{ }^{2}\right\} \mathrm{x}_{\mathrm{o}}+\left\{0.0503+0.0136 \mathrm{y}_{\mathrm{o}}{ }^{2}\right\} \mathrm{x}_{0}{ }^{3}\right], \\
& \mathrm{Q}_{\mathrm{y}} / \mathrm{Q}_{\mathrm{s}}=0.1127\left[\left\{1+0.5429 \mathrm{x}_{\mathrm{o}}{ }^{2}\right\} \mathrm{y}_{\mathrm{o}}-\left\{0.0598+0.00858 \mathrm{x}_{0}{ }^{2}\right\} \mathrm{y}_{\mathrm{o}}{ }^{3}\right], \\
& \mathrm{Q}_{\mathrm{x}} / \mathrm{Q}_{\mathrm{s}}=0.6156\left[\left\{1+0.0308 \mathrm{y}_{\mathrm{o}}{ }^{2}\right\} \mathrm{x}_{\mathrm{o}}-\left\{0.1314+0.0146 \mathrm{y}_{\mathrm{o}}{ }^{2}\right\} \mathrm{x}_{\mathrm{o}}{ }^{3}\right] .
\end{aligned}
$$

The button sensitivities for the above two chambers are plotted in Figs. 5 and 6. As seen from the figures and Eqs. (12) and (13), the most critical signals $Q_{y}$ for 8-mm and 5-mm chambers are only 0.045 and 0.022 of the unit $-\lambda y_{0} / h$. Compared to $Q_{y}$, the horizontal signals $Q_{x}$ are over 0.11 of the unit $-\lambda x_{0} / h$ for both chambers. Even if the normalized signals are not too small (because of the small values of $\mathrm{Q}_{\mathrm{s}}$ ), one should expect that the noise/signal ratios for $\mathrm{Q}_{y} / \mathrm{Q}_{s}$ and $\mathrm{Q}_{\mathrm{x}} / \mathrm{Q}_{\mathrm{s}}$ in Eqs. (12) and (13) are relatively large compared to those in Eq. (11).

\section{ACKNOWLEDGEMENTS}

The author appreciates G. Decker for his numerous suggestions for this work.

\section{REFERENCES}

[1] See, for example, W. K. H. Panofsky and M. Phillips, Classical Electricity and Magnetism (Addison-Wesley, Cambridge, MA, 1955) p. 290.

[2] See, for example, D. A. Edwards and M. J. Syphers, An Introduction to the Physics of High Energy Accelerators (John Wiley \& Sons, Inc, New York, 1993) p. 179. 


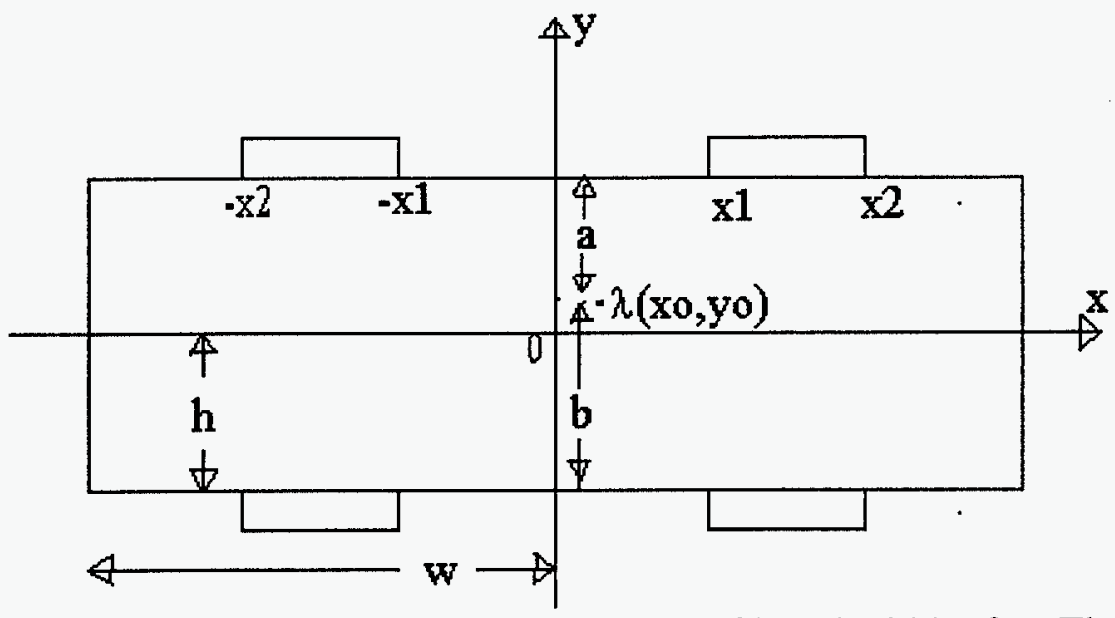

Fig. 1. Cross section of a beam chamber with a height of $h$ and width of $w$. The chamber is assumed to be grounded. The charge $\lambda$ at $\left(x_{0}, y_{0}\right)$ is the line-charge density in the 3-D geometry. The diameter of the four buttons for the BPM system is $\left(x_{2}-x_{1}\right)$, and $b=h+y_{0}$, $\mathrm{a}=\mathrm{h}-\mathrm{y}_{\mathrm{o}}$.

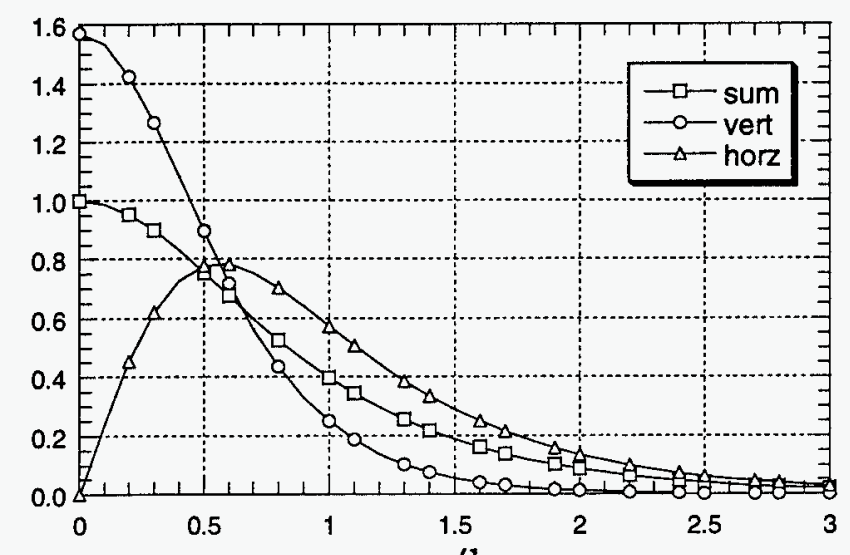

(a) charge densities

$\mathrm{x} / \mathrm{h}$

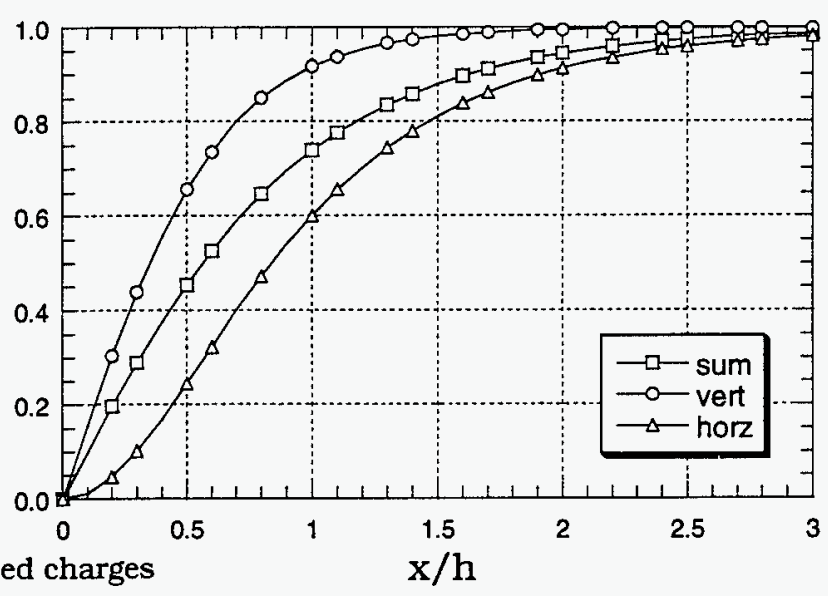

Fig. 2. (a) Induced charge densities of Eq. (10) and (b) induced charges integrated from 0 to $x / h$. The induced charges and densities corresponding to $Q_{s}, Q_{y}$, and $Q_{x}$ in Eq. (9) are denoted as sum, vert, and horz in the legends, respectively, with units of $-\lambda,-\lambda y_{0} / h$, and $-\lambda x_{0} / h$. 
(a) $Q_{s}$
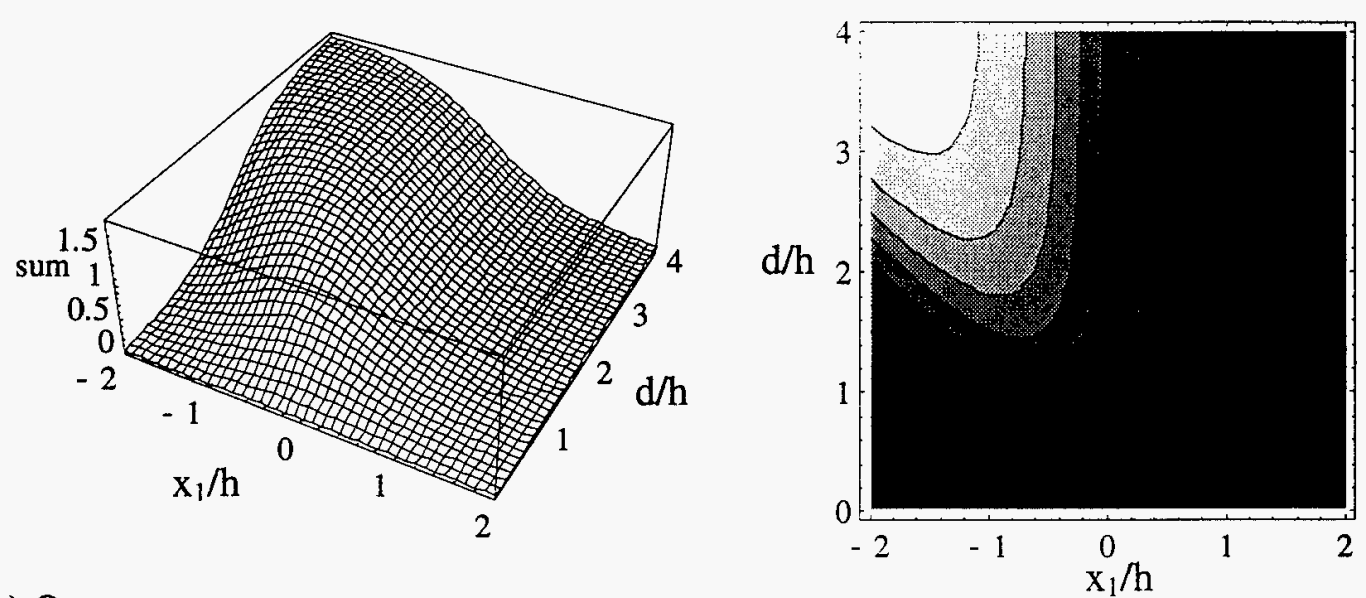

(b) $Q_{y}$
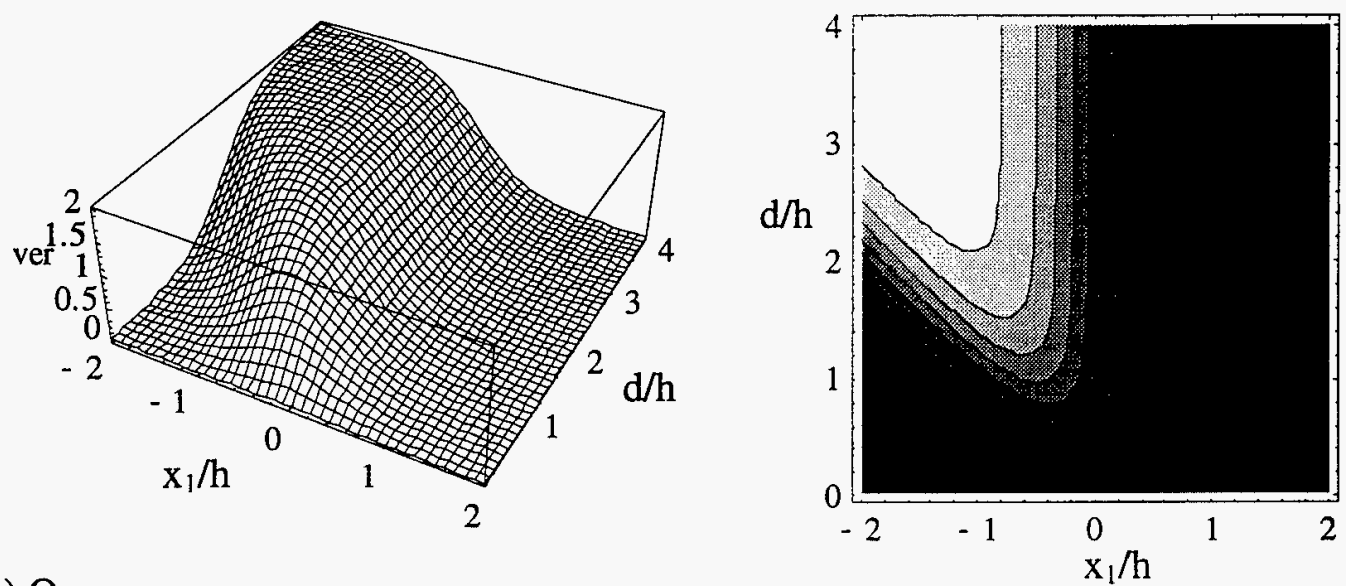

(c) $Q_{x}$
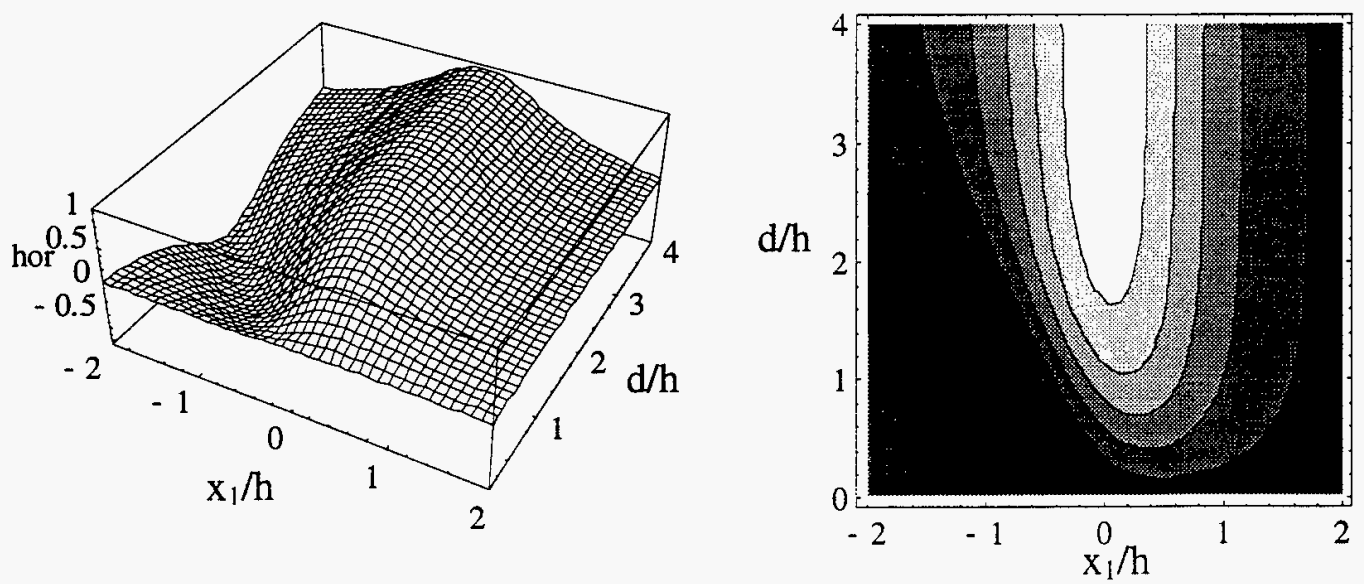

Fig. 3. 3-D plots of the induced charges for $Q_{s}, Q_{y}$, and $Q_{x}$ of Eq. (6) - (8) as functions of normalized button offset $x_{1} / h$ and button diameter $d / h$ on the left side, and their contour plots on the right side. The respective units for $Q_{s}$. $Q_{y}$, and $Q_{x}$ are $-\lambda,-\lambda y_{0} / h$, and $-\lambda x_{0} / h$. 


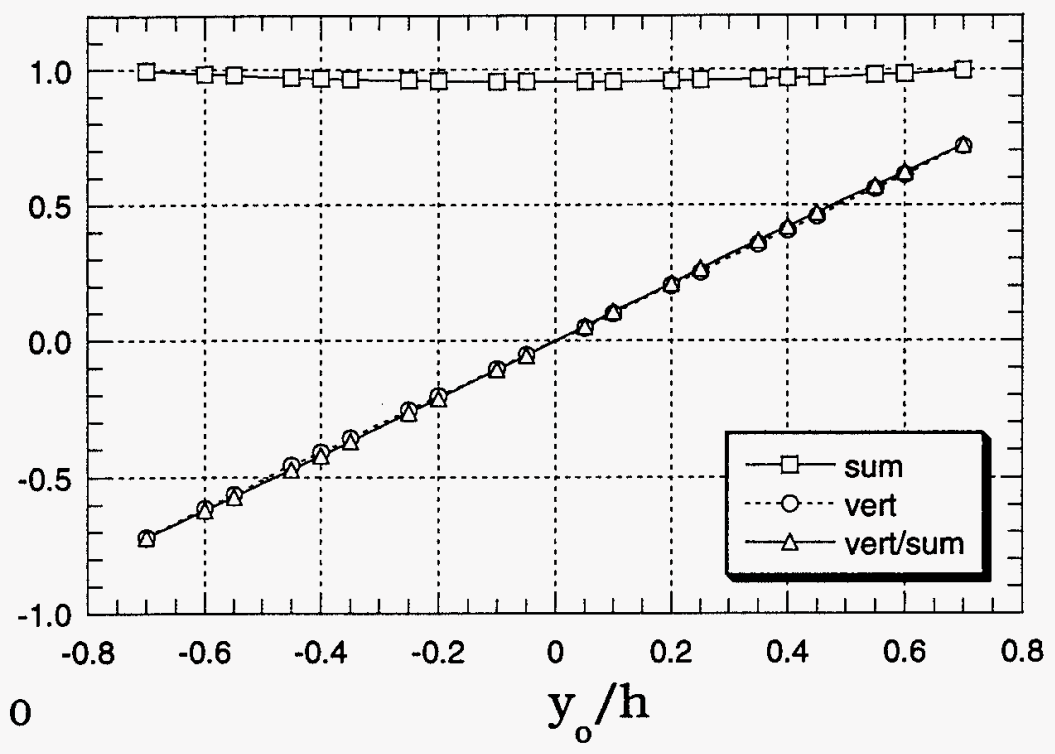

(a) $x_{0}=0$

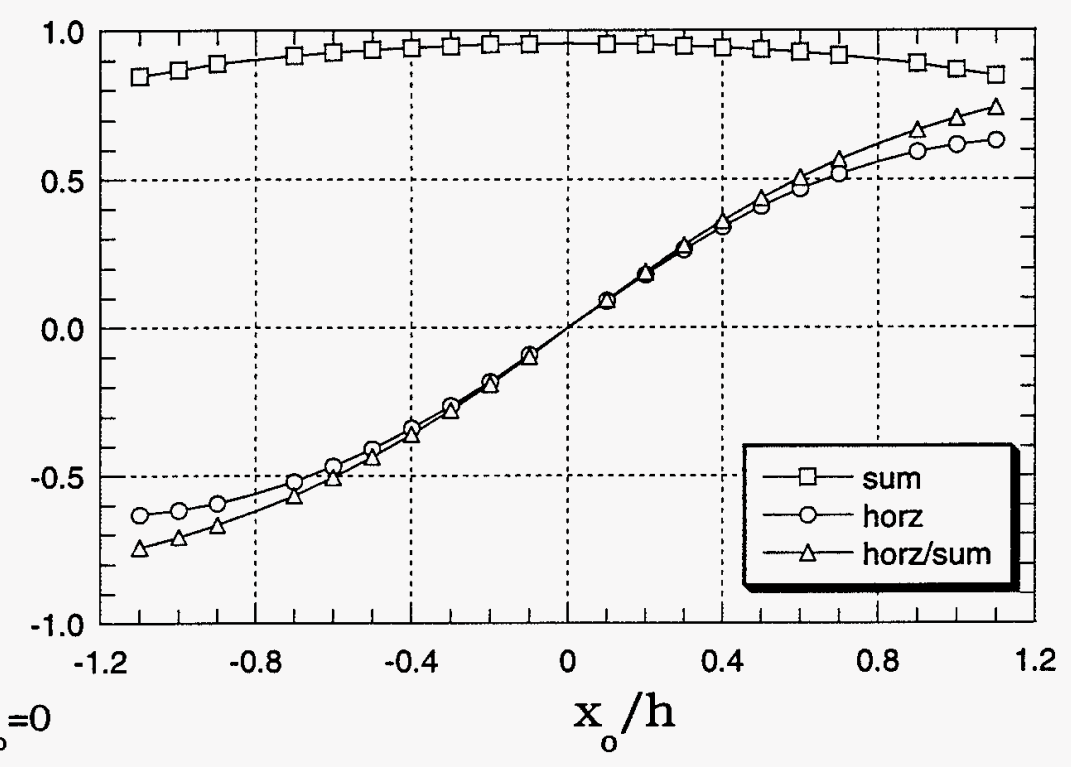

Fig. 4. For the optimized BPM configuration, normalized button positions of $x_{1} / h$ $=0$ and $x_{2} / \mathrm{h}=2$ (normalized diameter $\mathrm{d} / \mathrm{h}=2$ ), variations (a) $\mathrm{Q}_{\mathrm{s}}, \mathrm{Q}_{\mathrm{y}}$, and $\mathrm{Q}_{\mathrm{y}} / \mathrm{Q}_{\mathrm{s}}$ are plotted as a function of normalized vertical beam position $y_{0} / h$ for $x_{0}=0$, and (b) $\mathrm{Q}_{s}, \mathrm{Q}_{\mathrm{x}}$, and $\mathrm{Q}_{\mathrm{x}} / \mathrm{Q}_{\mathrm{s}}$ as a function of normalized horizontal beam position $\mathrm{x}_{\mathrm{o}} / \mathrm{h}$ for $y_{o}=0$. Here $Q_{s}, Q_{y}$, and $Q_{x}$ are denoted as sum, vert, and horz and their respective units are $-\lambda,-\lambda y_{0} / h$, and $-\lambda x_{0} / h$. Note that for small values of $x_{0} / h$ and $\mathrm{y}_{\mathrm{o}} / \mathrm{h}, \mathrm{Q}_{\mathrm{s}}, \mathrm{Q}_{\mathrm{y}}$, and $\mathrm{Q}_{\mathrm{x}}$ are over 0.9 of their respective units. 


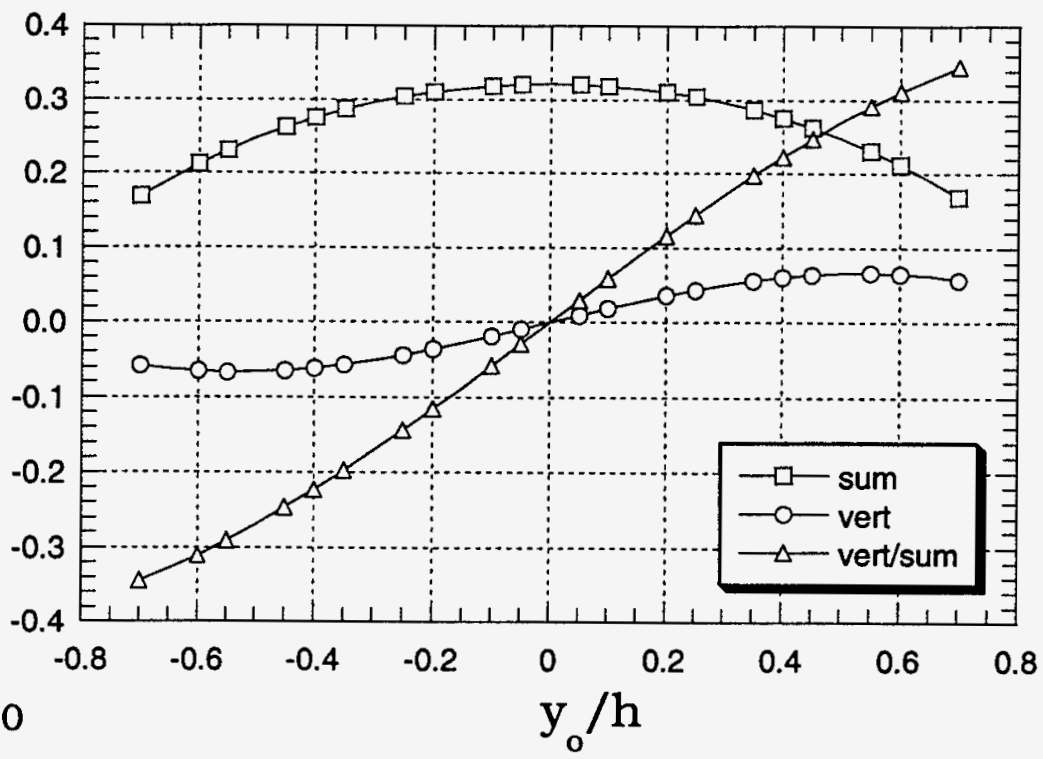

(a) $x_{0}=0$

$\mathrm{y}_{\mathrm{o}} / \mathrm{h}$

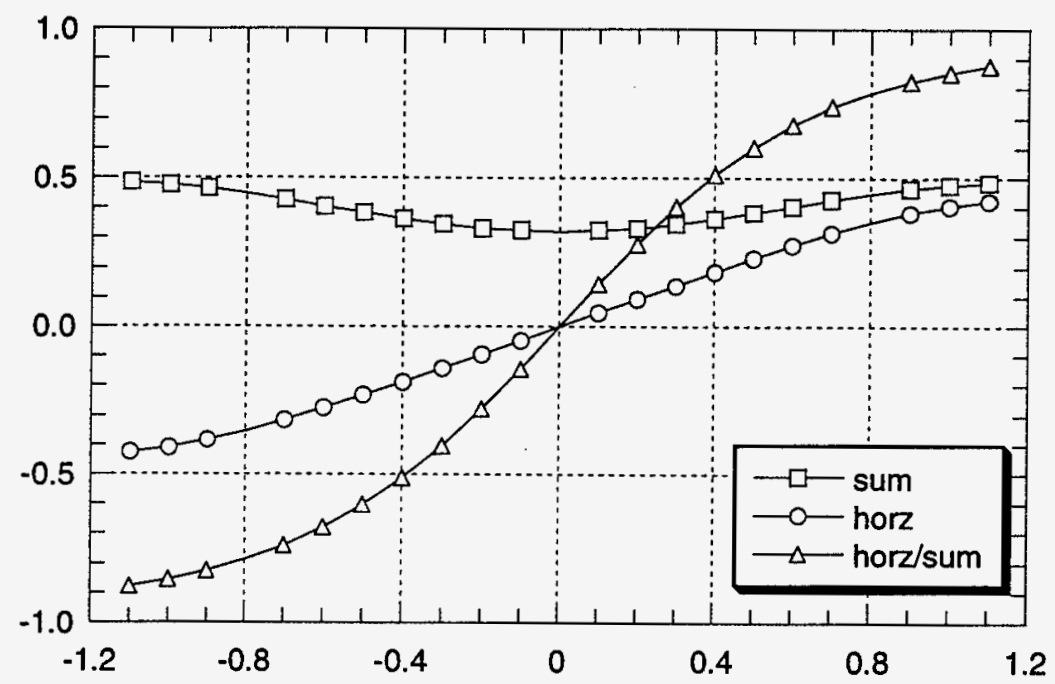

(b) $y_{0}=0$

$\mathrm{x}_{\mathrm{o}} / \mathrm{h}$

Fig. 5. For an 8-mm chamber $(\mathrm{h}=4 \mathrm{~mm})$ similar to an APS ID chamber with normalized button positions of $\mathrm{x}_{1} / \mathrm{h}=0.7075$ and $\mathrm{x}_{2} / \mathrm{h}=1.7075$ and button diameter $\left(\mathrm{x}_{2}-\mathrm{x}_{1}\right) \mathrm{h}=\mathrm{h}$, variations (a) $\mathrm{Q}_{\mathrm{s}}, \mathrm{Q}_{\mathrm{y}}$, and $\mathrm{Q}_{\mathrm{y}} / \mathrm{Q}_{\mathrm{s}}$ as a function of $\mathrm{y}_{0} / \mathrm{h}$ for $\mathrm{x}_{0}$ $=0$, and (b) $Q_{s}, Q_{x}$, and $Q_{x} / Q_{s}$ as a function of $x_{0} / h$ for $y_{o}=0$. Here $Q_{s}, Q_{y}$, and $Q_{x}$ are denoted as sum, vert, and horz and their respective units are $-\lambda,-\lambda y_{0} / h$, and $-\lambda x_{0} / h$. Note that for small values of $x_{0} / h$ and $y_{0} / h, Q_{s}, Q_{y}$, and $Q_{x}$ are only 0.32 , 0.05 , and 0.12 of their respective units and the button system is inefficient. 


\section{M98005248}

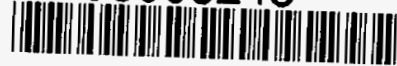

Report Number (14) LS - 266 (ANL)

Publ. Date (11) $\frac{19980327}{\text { DOE/ER, XF }}$
$\begin{aligned} & \text { Sponsor Code (18) } \\ & \text { UC Category (19) }\end{aligned}$

